\title{
Thema der nächsten Ausgabe:
}

\section{Business Partner - Mitten drin statt nur dabei}

\section{Möglichkeiten und Heraus- forderungen}

Das häufig propagierte Rollenbild des sogenannten „Business Partners“ hat die Praxis erreicht und in vielen Unternehmen zu Veränderungsprozessen im Controlling geführt. Aufbauend auf aktuellen Forschungsergebnissen diskutiert der Beitrag, welche Chancen dieses neue Selbstverständnis bietet und welche Hürden zu nehmen sind.

Lukas Goretzki, Martin Messner

\section{What it means to be a Business Partner?}

Die Bezeichnung hält sich hartnäckig in der Controlling-Community. Ob man damit überall vom selben Konzept spricht, ist jedoch nicht klar. Aus dem Blickwinkel der angelsächsischen Controlling-Welt versucht der Beitrag, die tatsächliche Bedeutung des Begriffs zu ergründen, und wirft auch einen Blick in die Zukunft des Business Partners.

Martin Quinn

\section{"Moving minds. Creating value."}

Früher hatte ein Controller den Ruf eines „Erbsenzählers“. Dieses Bild trifft auf die Controller bei der BASF nicht zu. Wolfgang Hagen, Senior Vice President Corporate Controlling bei der BASF, erläutert im Dialog mit Utz Schäffer den Weg, wie der Controller zum gleichberechtigten Partner wird. Das Konzept des Business Partnerings dient als Leitlinie.

\section{Springer Gabler}

\section{Empfohlen vom BVBC - Bundesverband der Bilanzbuchhalter und Controller e.V.}

2011, 1235S. Geb.

$€(D) 149,95 \mid €$ (A) $154,15 \mid{ }^{*}$ sFr 187,00

ISBN 978-3-8349-1989-2

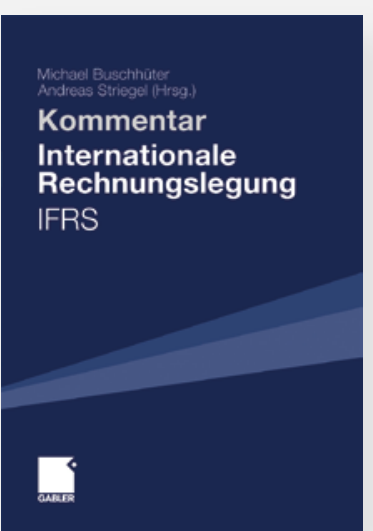

Michael Buschhüter, Andreas Striegel (Hrsg.) Internationale Rechnungslegung - IFRS Kommentar In Deutschland sind alle kapitalmarktorientierten Unternehmen zur Aufstellung von IFRS Abschlüssen verpflichtet. Zahlreiche weitere Unternehmen stellen IFRS Abschlüsse auf freiwilliger Basis auf. Unternehmen und deren Berater müssen daher die IFRS sicher beherrschen. Dieser Kommentar ist ein wichtiger Ratgeber in allen Fragen der Praxis. vorbehalten. 